\title{
Combined cetuximab and celecoxib treatment exhibits a synergistic anticancer effect on human oral squamous cell carcinoma in vitro and in vivo
}

\author{
MING QIAN ${ }^{1}$, DONGHUA QIAN ${ }^{2}$, HONGYU JING $^{2},{\text { YANG } \text { LI }^{2}, \text { CHENGYUAN MA }^{3} \text { and YANMIN ZHOU }}^{4}$ \\ ${ }^{1}$ Prosthodontics Department of the Stomatological Hospital, Jilin University; Departments of ${ }^{2}$ Respiration and \\ ${ }^{3}$ Neurosurgery, The First Hospital of Jilin University; ${ }^{4}$ Implantology Department of the Stomatological Hospital, \\ Jilin University, Changchun, Jilin 130021, P.R. China
}

Received March 28, 2014; Accepted May 19, 2014

DOI: $10.3892 /$ or.2014.3334

\begin{abstract}
The aim of the present study was to evaluate the potency of epidermal growth factor receptor (EGFR) pathway inhibition achieved by combining cetuximab (CET), an anti-EGFR monoclonal antibody, and celecoxib (CXB), a cyclooxygenase-2 (COX-2) inhibitor, in oral squamous cell carcinoma (OSCC) in vitro and in vivo. The OSCC cell line, HSC3, was treated with CET $(0-400 \mu \mathrm{g} / \mathrm{ml}), \mathrm{CXB}(0-40 \mu \mathrm{M})$, or a combination of both at a range of concentrations. Cell proliferation, apoptosis, migration and invasion were determined to assess the anticancer effects in vitro. The in vivo effects of CET and CXB on tumor cell growth were examined using an OSCC xenograft nude mouse model. In addition, downstream protein expression levels of EGFR, p-EGFR, PI3K, p-PI3K, AKT and p-Akt were evaluated by western blot analysis. It was found that the combination of low concentrations of CET and CXB significantly suppressed the proliferation, migration and invasion of the HSC3 tumor cells and decreased PEG2 production and VEGF expression in vitro, and inhibited tumor growth in vivo compared to the action of either agent alone. The results also showed that this combination significantly induced apoptosis and increased caspase- 3 and caspase- 8 activity compared to the action of either agent alone $(\mathrm{P}<0.01)$. Furthermore, the combination treatment significantly reduced the expression of p-EGFR, p-PI3K and p-Akt in the HSC 3 cell line, which may contribute to the inhibition of tumor growth. Taken together, our findings revealed that the additive combination of CET and CXB is a potential drug candidate for the treatment of OSCC.
\end{abstract}

Correspondence to: Professor Yanmin Zhou, Implantology Department of the Stomatological Hospital, Jilin University, Changchun, Jilin 130021, P.R. China

E-mail: zhouyanmin528@163.com

Key words: cetuximab, celecoxib, oral squamous cell carcinoma, EGFR

\section{Introduction}

Oral squamous cell carcinoma (OSCC) accounts for approximately $4 \%$ of all carcinomas in men and $2 \%$ in women worldwide, with geographical variation in frequency (1). Although advances in early diagnosis and multimodal treatments, including surgery, chemotherapy and irradiation have been achieved, the 5-year survival rate of OSCC patients has remained at 50-60\% due to recurrence and metastasis (2). Since conventional cytotoxic therapies act upon rapidly dividing normal cells as well as malignant cells, which results in the significant morbidity in patients with solid tumors including OSCC, this method is of limited benefit for survival (3). Therefore, the development of improved anticancer therapies that effectively and specifically target epithelial tumor cells while minimizing the toxic side effects commonly associated with conventional cytotoxic therapies is urgently needed.

With the enhanced understanding of key cellular pathways involved in tumor growth, progression and cell death, molecular targeted therapies have been exploited (4). Recently, novel treatments aimed to target specific molecules, such as epidermal growth factor receptor (EGFR), aberrantly expressed in OSCC, have been investigated and tested in clinical trials at several research centers with promising results (5). For many years, the EGFR has been investigated as a major target for the treatment of uncontrolled tumor growth (6). The EGFR, a glycosylated transmembrane, is involved in regulating cell growth, differentiation and the survival of cells (7). Increasing evidence has shown that EGFR is often overexpressed in human malignancies such as gastrointestinal and abdominal carcinomas, lung carcinomas, carcinomas of the reproductive tract, melanomas, glioblastomas and thyroid carcinomas, as well as OSCC $(8,9)$, yet absent in hematopoietic cells (10). Although data are inconsistent, overexpression is often associated with an aggressive tumor phenotype and a poor clinical prognosis. Growth factor-induced EGFR signaling is important in many normal cellular processes with effects ranging from apoptosis to migration and differentiation $(10,11)$. To target tumor cell proliferation or growth via EGFR, monoclonal antibodies (mAbs) against this receptor have been developed (11-13). These mAbs are highly specific 
with few side effects and may result in synergistic effects when combined with chemotherapy and radiation (14). Among these agents cetuximab (CET) (Erbitux ${ }^{\circledR}, \mathrm{C} 225$; ImClone LLC) is a human-murine chimeric $\mathrm{IgG} \mathrm{mAb}$ that has been approved by the Food and Drug Administration (FDA) for treatment of colorectal cancer as a single drug or in combination with chemotherapy and for HNSCC in combination with radiation therapy or as a monotherapy after failure of platinum-based therapy (2004 approval). CET, a 152-kDa molecule, is composed of two 449-amino-acid heavy chains and of two 214-amino-acid light chains interfaced both by covalent (disulfide) and noncovalent bonds (15). It competitively binds to the extracellular domain of EGFR, preventing tyrosine kinase activation, inhibiting cell growth and inducing apoptosis (16). Preclinical studies suggest that CET inhibits the proliferation of cancer cell lines expressing EGFR, and increases the cytotoxic activity of chemotherapy and radiation $(14,17)$. Unfortunately, only $10-20 \%$ of cancer patients were responsive to and clinically benefited from anti-EGFR mAbs due to intrinsic and acquired resistance (18). Thus, combined treatment of CET with chemotherapy or other drugs may be a beneficial strategy with which to increase the therapeutic effect on OSCC.

Celecoxib (CXB) is a cyclooxygenase 2-selective nonsteroidal anti-inflammatory drug (NSAID) that has been approved for the treatment of adult arthritis, and has been found to exhibit therapeutic effects on various types of cancers (19). Currently, CXB is widely being tested in clinical trials for its therapeutic activity against various cancers as a single agent and also in combination with other agents $(20,21)$. Recently, combined EGFR and COX-2 inhibition trials have been completed and demonstrate that this combination could inhibit head and neck squamous cell carcinoma (HNSCC) growth and decrease drug resistance (22).

Therefore, in this context, in the present study we selected CXB as a COX-2 inhibitor in combination with CET for suppressing EGFR and COX-2 expression and for simultaneously reducing the doses of both drugs for the treatment of OSCC. We also evaluated the feasibility of CXB in combination with CET in inhibiting OSCC cell growth in vitro and in vivo, and revealed the underlying molecular mechanisms of $\mathrm{CET}$ in combination with $\mathrm{CXB}$ involved in the induction of apoptosis.

\section{Materials and methods}

Reagents. $\mathrm{CXB}$, one type of COX-2 inhibitor, was purchased from Pfizer Corporation Inc. (New York, NY, USA). CET was provided by Merck Serono (Darmstadt, Germany).

Cell culture. HSC3, an OSCC cell line, was obtained from the American Type Culture Collection (ATCC; Manassas, VA, USA). The cells were maintained in Dulbecco's modified Eagle's medium (DMEM; Invitrogen, Carlsbad, CA, USA) supplemented with $10 \%$ fetal bovine serum (FBS; Invitrogen) in a humidified atmosphere of $5 \% \mathrm{CO}_{2}$ at $37^{\circ} \mathrm{C}$.

Cell viability assay. HSC3 cells grown in monolayers were harvested and dispensed in 96-well culture plates in $100 \mu 1$ of DMEM at a concentration of $5 \times 10^{3}$ cells per well. After $24 \mathrm{~h}$, different drug concentrations of CET $(0-400 \mu \mathrm{g} / \mathrm{ml})$,
CXB $(0-40 \mu \mathrm{M})$, or both $(0-200 \mu \mathrm{g} / \mathrm{ml}$ CET plus $20 \mu \mathrm{M}$ $\mathrm{CXB})$ were added to the cells. Cell viability was assessed using 3-(4,5-dimethylthiazol-2-yl)-2,5 diphenyltetrazolium bromide (MTT) colorimetric assay at $490 \mathrm{~nm}$ with minor modifications according to a previous study (23). This assay was carried out in triplicate. The inhibition rate was calculated according to the following formula: Inhibition rate $(\%)=[1$ - (average absorbance of the experimental group/ average absorbance of the blank control group)] x $100 \%$.

Cell apoptosis assay. To evaluate the change in the apoptotic index, terminal transferase dUTP nick end labeling (TUNEL) assay was used. HSC3 cells $\left(1 \times 10^{5}\right.$ cells $/ \mathrm{ml}$ in 6 -well plates) were cultured and treated with their respective half maximal inhibitory concentration $\left(\mathrm{IC}_{50}\right)$ values for $\mathrm{CET}, \mathrm{CXB}$, or both for $48 \mathrm{~h}$. After fixation in $4 \%$ paraformaldehyde/PBS ( $\mathrm{pH}$ 7.2) for $15 \mathrm{~min}$ at room temperature and permeabilization in a permeabilization buffer for 2-5 min, the assay was performed on cells on coverslips using a commercially available in situ apoptosis detection kit (In situ Cell Death Detection kit, POD, Roche Diagnostic, Branchburg, NJ, USA). After applying anti-FITC HRP conjugate at $37^{\circ} \mathrm{C}$ for $30 \mathrm{~min}$, diaminobenzidine (DAB) was applied to generate an insoluble colored substrate at the site of DNA fragmentation for $10 \mathrm{~min}$. Apoptosis indices of both cell types for each treatment were calculated as the percentage of cells displaying TUNEL labeling out of the total number of nuclei. In addition, we also detected caspase- 3 and -8 activity by ELISA as an additional indicator of apoptosis.

Caspase activity assay. The activity of caspase- 3 and -8 was measured using the Caspases Colorimetric Protease Assay kits (Millipore, Billerica, MA, USA) as per the manufacturer's instructions. Briefly, cells were treated with their respective half maximal inhibitory concentration $\left(\mathrm{IC}_{50}\right)$ values for CET, $\mathrm{CXB}$, or both for $24 \mathrm{~h}$, then washed twice with ice-cold PBS (pH 7.2) and harvested by centrifugation at $700 \mathrm{x}$ for $10 \mathrm{~min}$. The cell pellets were then lysed in $150 \mu \mathrm{l}$ buffer provided in the kit. Protein concentrations of the lysates were determined using the Lowry method. Then, an aliquot of lysates $(80 \mu \mathrm{l})$ was incubated with $10 \mu \mathrm{l}$ substrate of each caspase at $37^{\circ} \mathrm{C}$ for $2 \mathrm{~h}$. Samples were analyzed at $405 \mathrm{~nm}$ by a microplate reader (Thermo Fisher Scientific Inc., Waltham, MA, USA).

Migration assays. To assess the effect of CET combination with $\mathrm{CXB}$ on cell migration, a wound-healing assay was performed. In brief, migration chambers $(8-\mu \mathrm{m}$ pores; Corning) were coated for $1 \mathrm{~h}$ at $37^{\circ} \mathrm{C}$ with either $10 \mu \mathrm{g} / \mathrm{ml}$ purified plasma fibronectin or PBS and blocked with migration buffer [3:1 of DMEM:F12 and 0.5\% (w/v) BSA] for $1 \mathrm{~h}$. Cells were harvested following treatment with their respective half maximal inhibitory concentration $\left(\mathrm{IC}_{50}\right)$ values for CET, CXB, or both for $48 \mathrm{~h}$. Then, $1 \times 10^{5}$ cells were resuspended in $100 \mu \mathrm{l}$ of migration buffer, placed in the chambers and incubated at $37^{\circ} \mathrm{C}$ for $4 \mathrm{~h}$. Non-migrated cells were removed, samples were fixed in $10 \%$ (v/v) buffered formalin, and stained with haematoxylin and mounted on glass slides. Using an inverted phase-contrast microscope (Leica DMR, Germany), the number of migrated cells was determined by counting 5 randomly selected fields. 
Invasion assays. The invasiveness of the HSC3 cells following treatment with CET, CXB or CET combined with CXB in vitro was measured using $\mathrm{BD}$ BioCoat ${ }^{\mathrm{TM}}$ Matrigel invasion chambers (Becton Dickinson Labware, Bedford, MA, USA) according to the manufacturer's instructions. In brief, filters were precoated on the upper side with Matrigel provided in the kits $(1 \mathrm{mg} / \mathrm{ml})$. The lower chamber was filled with culture media containing $10 \%$ FBS. Cells $\left(3 \times 10^{5}\right)$ treated with the indicated drugs in low serum media [3:1 of DMEM:F12 with $0.5 \%$ (v/v) FCS and 2\% (w/v) L-glutamine] in the inner chamber and KGM was used as a chemo-attractant. Plates were incubated for $16 \mathrm{~h}$ at $37^{\circ} \mathrm{C}$, and the invaded cells were observed with an immunofluorescence microscope by counting the cells that had invaded into the bottom of the cell culture insert. We also detected MMP-9 and MMP-2 protein expression by western blotting as an additional indicator of invasion and migration.

Measurement of prostaglandin-E2 (PGE2) production and VEGF expression. PGE2 synthesis was determined by competitive enzyme-linked immunosorbent assay (ELISA) as previously described with minor modification (23). In brief, HSC3 cells were treated with their respective half maximal inhibitory concentration $\left(\mathrm{IC}_{50}\right)$ values for $\mathrm{CET}, \mathrm{CXB}$, or their combination for $48 \mathrm{~h}$ in 12-well plates, and then the culture media were centrifuged to remove cell debris. Cell-free culture media were collected at the indicated time, then PGE2 levels were measured by competitive ELISA as described by the kit manufacturer (Cayman Chemical, Ann Arbor, MI, USA) using an ELISA reader ( $\mu$ Quant; BioTek Instruments, Inc., Winooski, VT, USA).

HSC 3 cells were treated with their respective half maximal inhibitory concentration $\left(\mathrm{IC}_{50}\right)$ values for $\mathrm{CET}, \mathrm{CXB}$, or their combination for $48 \mathrm{~h}$ in 24-well plates, and then the culture media were centrifuged to remove cell debris. Cell-free culture media were collected at indicated time. Protein levels of vascular endothelial growth factor (VEGF) in the cell supernatant were determined by the Human VEGF ELISA kit (Yanyu, Shanghai, China) according to the manufacturer's instructions. Samples were measured in triplicate and were properly diluted to ensure that the measured values were within the concentration range of the standard curve.

Tumor xenograft assay. To assess in vivo the combined effect of CET and CXB on OSCC, we used an OSCC xenotransplanted nude mouse tumorigenesis model. For inoculation of OSCC cells, the detached HSC 3 cells were diluted and emulsified with medium to a final cell concentration of $5 \times 10^{7}$ cells/ $\mathrm{ml}$, and the $200 \mu \mathrm{l}$ emulsion was then inoculated subcutaneously into the right flank of a total of 80 female BALB/c nude mice (6-8 weeks of age; weight $200 \mathrm{mg}$; Laboratory Animal Center of Jilin University, Changchun, China). The mice were maintained in an environment complying with the NIH guidelines for the care and use of laboratory animals, following a protocol approved by the Ethics Committees of the Disease Model Research Center, Jilin University. All animals were divided into 4 groups (10 mice/group) when the volume of the ensuing mass reached $75-100 \mathrm{~mm}^{3}$. The control group received $1 \%$ polysorbate resuspended in deionized water. The other three groups were treated with CXB $(4.56 \mathrm{mg} / \mathrm{kg}$ body weight), CET (1 mg/kg body weight), or CXB plus CET $(2.5 \mathrm{mg} / \mathrm{kg}$ plus $0.5 \mathrm{mg} / \mathrm{kg}$ body weight, respectively) intraperitoneally on alternative days for 3 weeks. Each mouse was weighed every day to evaluate the side effects of the administrations. The lengths and widths of the tumors were measured with a caliper every 7 days, and the tumor volume (in cubic millimeters) was calculated. At the end of 7 days, the animals were euthanized using chloroform and their spleen tissues were collected and cultured for a splenocyte surveillance study (23). In addition, each tumor was excised and weighed when the mice were sacrificed. Parts of each tumor tissue were wax embedded for $\mathrm{H} \& \mathrm{E}$ staining to study cell apoptosis in vivo by TUNEL.

Western blot analysis. HSC3 cells were treated with their respective $\mathrm{IC}_{50}$ values for $\mathrm{CET}, \mathrm{CXB}$ or their combination for $48 \mathrm{~h}$. The cells were then homogenized in lysis buffer (Tris- $\mathrm{HCl}$ $50 \mathrm{mmol} / \mathrm{l}$, EDTA $5 \mathrm{mmol} / \mathrm{l}, \mathrm{NaCl} 150 \mathrm{mmol} / \mathrm{l}$, sodium deoxycholate $1 \%, \mathrm{Na}_{3} \mathrm{VO}_{4} 500 \mu \mathrm{mol} / \mathrm{l}$, Triton X-100 0.5\%, AEBSF $10 \mu \mathrm{mol} / \mathrm{l}, \mathrm{NaF} 10 \mathrm{mmol} / \mathrm{l})$ on ice. The homogenates were then centrifuged at $14,000 \mathrm{rpm}$ at $4^{\circ} \mathrm{C}$ for $30 \mathrm{~min}$, and the supernatants were collected for protein concentration determination using the Bradford reagent (Sigma). Cell extracts (50 $\mu \mathrm{g}$ of protein) were separated on a sodium dodecyl sulfate-polyacrylamide electrophoretic gel (SDS-PAGE) and transferred to nitrocellulose membranes, which were blocked in $3 \%$ bovine serum albumin (BSA) for $2 \mathrm{~h}$. After blocking, the membranes were incubated with primary antibodies overnight at $4^{\circ} \mathrm{C}$ for $2 \mathrm{~h}$, and then with horseradish peroxidase-conjugated secondary antibody for $2 \mathrm{~h}$ at room temperature. Protein bands were visualized with enhanced chemiluminescence reagent (ECL; GE Healthcare, Velizy-Villacoublay, France). Blots were stripped and reprobed with anti- $\beta$-actin to control for loading variations. Quantity One ${ }^{\circledR}$ Software (Bio-Rad) was used for quantification of the protein bands. For western blot analysis, the following antibodies were used: a mouse monoclonal anti- $\beta$-actin, a mouse monoclonal anti-MMP-9 and a mouse monoclonal anti-MMP-2 (Sigma Aldrich, St. Louis, MO, USA), and mouse monoclonal anti-AKT, mouse monoclonal anti-phosphorylated (p)-AKT, mouse monoclonal anti-EGFR, mouse monoclonal anti-p-EGFR, mouse monoclonal anti-PI3K, mouse monoclonal anti-p-PI3K, and horseradish peroxidase-conjugated goat anti-mouse IgG (Santa Cruz Biotechnology, Santa Cruz, CA, USA).

Statistical analysis. Data from at least three independent experiments are expressed as mean \pm SD. Statistical comparison of more than two groups was performed using one-way ANOVA followed by a Tukey's post hoc test. All statistical tests were two-sided, and a P-value of $<0.05$ was considered indicative of a statistically significant difference. Statistical analyses were undertaken using the SPSS ${ }^{\circledR}$ Statistical Package, version 13.0 (SPSS Inc., Chicago, IL, USA) and GraphPad Prism, version 5.01 (GraphPad $^{\circledR}$ software, San Diego, CA, USA) for Windows.

\section{Results}

Effect of CET in combination with CXB on OSCC proliferation. To evaluate the effect of CET, CXB, and the combination on the cell viability of OSCC cancer cells in vitro, HSC3 cells were treated with increasing concentrations of CET 


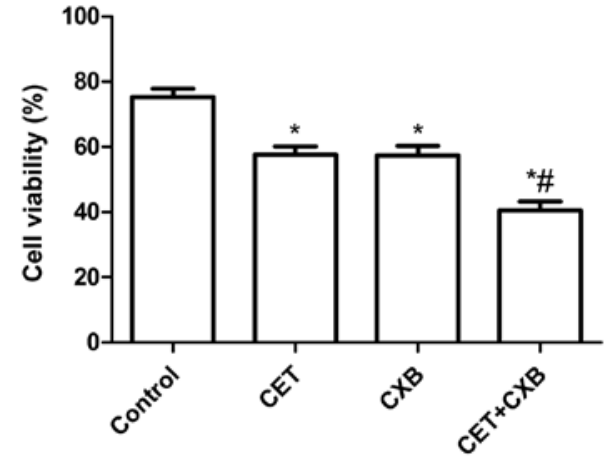

Figure 1. Effect of cetuximab (CET) and celecoxib (CXB) individually and in combination on the inhibitory rate of $\mathrm{HSC} 3$ cell viability. Inhibitory rate of HSC 3 cell viability was determined by the MTT assay when HSC 3 cells were treated with their $\mathrm{IC}_{50}$ concentration with CXB and CTX individually or the combination of the two for $48 \mathrm{~h}$. Data are expressed as the means $\pm \mathrm{SD}$. ${ }^{*} \mathrm{P}<0.05$ vs. control, ${ }^{\#} \mathrm{P}<0.05$ vs. CXB alone.

(0-400 $\mu \mathrm{g} / \mathrm{ml})$, CXB $(0-40 \mu \mathrm{M})$, or both $(0-200 \mu \mathrm{g} / \mathrm{ml}$ CET plus $20 \mu \mathrm{M} \mathrm{CXB}$ ). Treatment with CTX alone resulted in an $\mathrm{IC}_{50}$ value of $210.35 \pm 15.28 \mu \mathrm{g} / \mathrm{ml}$. Treatment with CXB alone also resulted in an $\mathrm{IC}_{50}$ value of $25.5 \pm 1.780 \mu \mathrm{M}$. Combination treatment $(0-200 \mathrm{ng} / \mathrm{ml} \mathrm{CET}$ plus $20 \mu \mathrm{M} \mathrm{CXB})$ resulted in a leftward shift in the concentration-response curve such that the $\mathrm{IC}_{50}$ value was reduced to $100.88 \pm 7.98 \mu \mathrm{g} / \mathrm{ml}$. In addition, our results also demonstrated that CET, CXB and the combination inhibited cell proliferation dose-dependently Based on the results, we selected the respective $\mathrm{IC}_{50}$ values of the drugs for further treatments throughout the study.

We next examined whether the combination of relatively low concentrations of CET and CXB could additively or synergistically inhibit OSCC cell proliferation in vitro with their respective $\mathrm{IC}_{50}$ values for CET, CXB or the combination. As shown in Fig. 1, the inhibitory rate of the combination treatment group was higher than the rates of the single drug groups $(\mathrm{P}<0.01)$. There was no statistically significant difference between the CET group and the CXB group ( $\mathrm{P}>0.05)$. In addition, the inhibitory rate of the combination treatment group was higher than that of the control group (all $\mathrm{P}<0.05$ ).

Effect of CET in combination with CXB on OSCC apoptosis. To verify whether CET and CXB exert an anticancer effect via induction of apoptosis, apoptotic cancer cells in vitro were detected with a light microscope using a TUNEL technology. The assays were performed on HSC 3 cells treated with CET or $\mathrm{CXB}$ alone and the combination of the two agents at their respective $\mathrm{IC}_{50}$ values. HSC3 cells treated with CET, CXB or the combination had an increased percentage of apoptotic cells compared with the untreated cells $(\mathrm{P}<0.05$, Fig. 2A). In addition, the low-dose combination resulted in an even higher percentage of apoptotic cells than did the higher doses of either drug alone. There was no significant difference between the CET group and the CXB group in the induction of OSCC apoptosis. These data were consistent with the results from the MTT assay, which indicated an additive effect of CET and $\mathrm{CXB}$ in inducing cell death via apoptosis.

To explore the possible mechanism involved in the induction of cell apoptosis of CTX in combination with CXB, caspase-3, -8 and -9 activity was determined by ELISA.

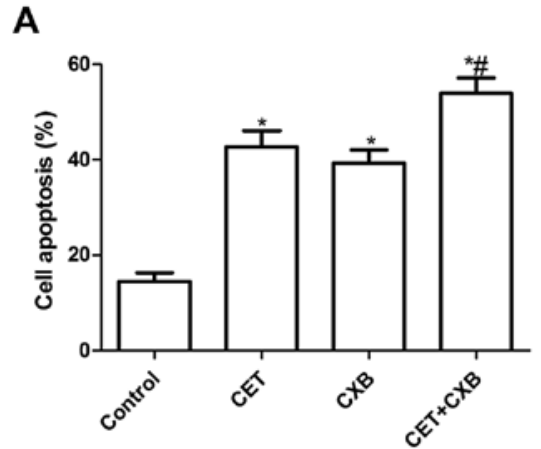

B

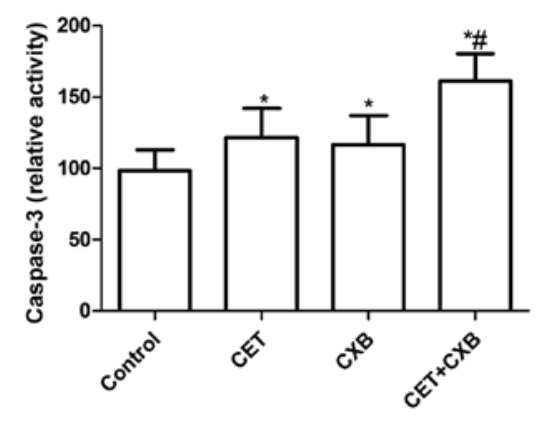

C

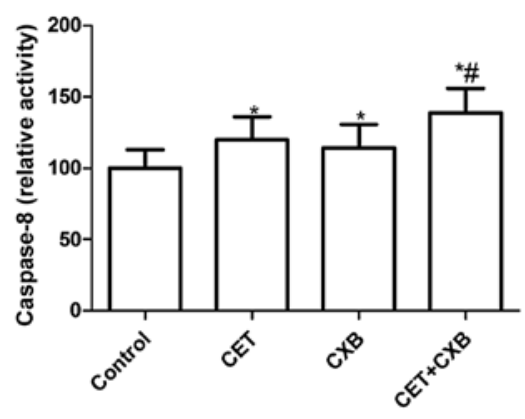

D

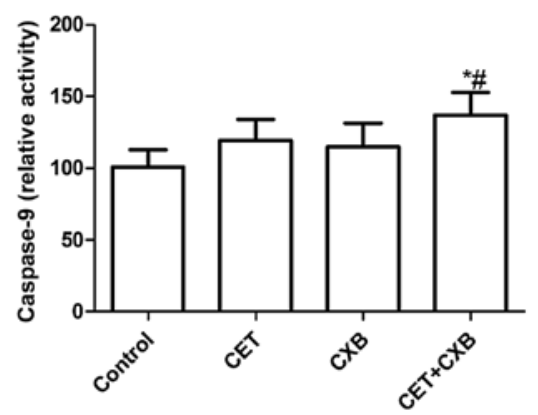

Figure 2. Effect of cetuximab (CET) and celecoxib (CXB) treatment alone or in combination on the cell apoptosis of HSC3 cells. (A) Cell apoptosis of HSC3 cells was determined $48 \mathrm{~h}$ after treated with CET or CXB alone or in combination. (B) Caspase-3, (C) caspase-8 and (D) caspase-9 activity of HSC 3 cells was measured by ELISA. Data are expressed as the means \pm SD. ${ }^{*} \mathrm{P}<0.05$ vs. control, ${ }^{\#} \mathrm{P}<0.05$ vs. $\mathrm{CXB}$ alone.

The results showed that caspase- $-3,-8$ and -9 activity was significantly increased in the treatment group compared to the control group ( $\mathrm{P}<0.01$, Fig. 2B-D). Importantly, caspase-3, -8 and -9 activity was significantly increased in the combination group compared to the activity in the single treatment groups ( $\mathrm{P}<0.05$, Fig. 2B-D). 
A

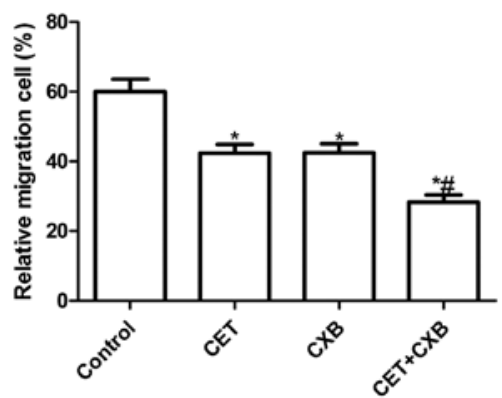

C

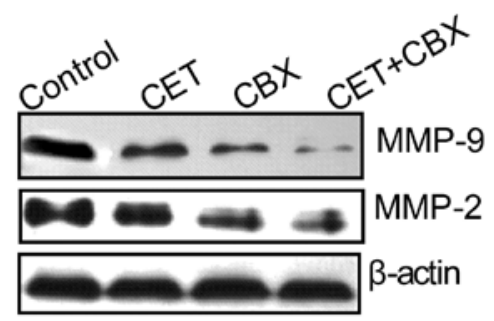

B

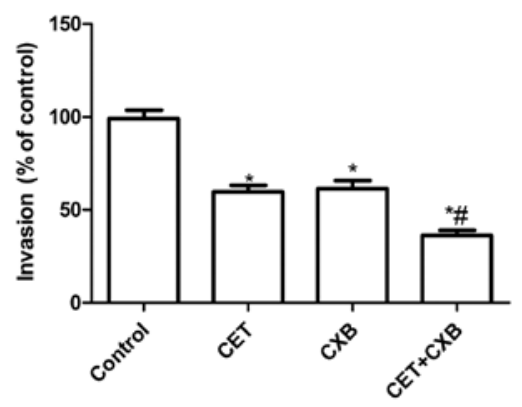

D

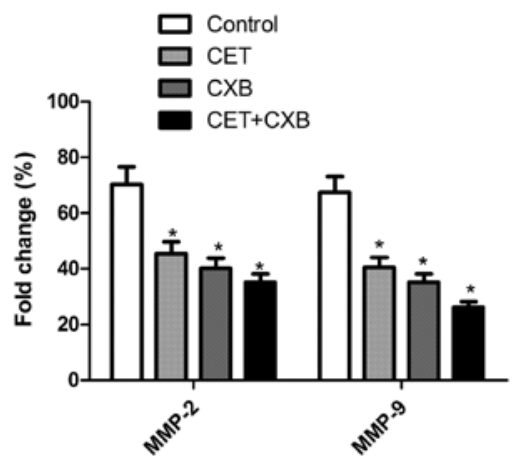

Figure 3. Effect of cetuximab (CET) and celecoxib (CXB) single treatment and in combination on the cell migration and invasion of HSC3 cells. (A) Cell migration and (B) invasion capacities of the HSC3 cells were determined after treatment with CET or CXB alone or the combination. (C and D) MMP-2 and MMP-9 expression was determined $72 \mathrm{~h}$ after treatment with CET and CXB alone or the combination. Data are expressed as the means \pm SD. ${ }^{*}<0.05$ vs. control, ${ }^{\#} \mathrm{P}<0.05$ vs. CXB alone.

A

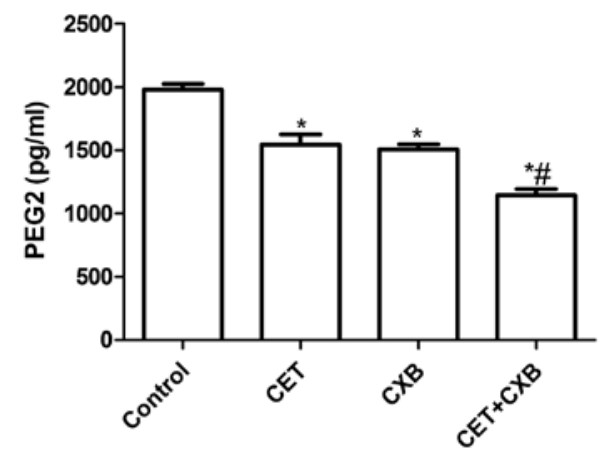

B

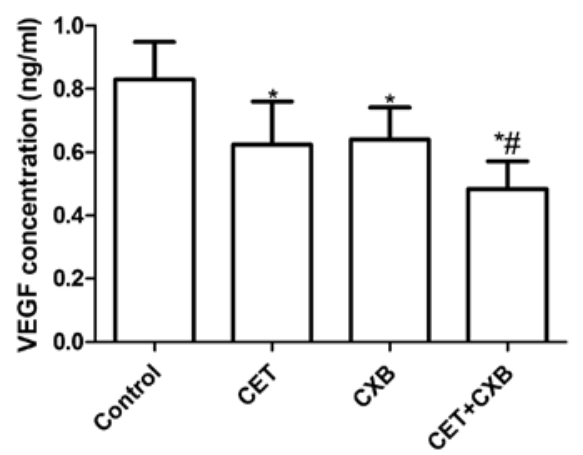

Figure 4. Effect of cetuximab (CET) or celecoxib (CXB) alone and in combination on prostaglandin-E2 (PGE2) production and VEGF expression in HSC3 cells. (A) PGE2 production and (B) VEGF expression were assessed by ELISA. Data are expressed as means $\pm \mathrm{SD}$. ${ }^{*} \mathrm{P}<0.05$ vs. control, ${ }^{*} \mathrm{P}<0.05$ vs. CXB alone.

Effect of CET in combination with CXB on OSCC migration and invasion. To ascertain the inhibitory effect of CET in combination with $\mathrm{CXB}$ on OSCC cell motility in vitro, a wound-healing assay was performed. After $48 \mathrm{~h}$, cells in the CET group, the CXB group and the combination CET and $\mathrm{CXB}$ group exhibited a significantly reduced migration capacity compared to the control group. Compared to the CET or the $\mathrm{CXB}$ group, the cells in the combination group exhibited significantly reduced migration of HSC3 cells $(\mathrm{P}<0.05$; Fig. 3A).

The ability of CET in combination with $\mathrm{CXB}$ to reduce the invasiveness of OSCC was further investigated by the Transwell system assay. Cell invasion was also significantly decreased in the treatment groups compared to the control group $(\mathrm{P}<0.05$, Fig. 3B). Compared to the $\mathrm{CXB}$ or the $\mathrm{CET}$ group, the combination treatment group greatly inhibited HSC3 cell invasion $(\mathrm{P}<0.05$, Fig. 3B).

To determine the potential mechanisms involved in the inhibition of cell migration and invasion in vitro, MMP-9 and MMP-2 protein expression was examined by western blotting. Western blot analysis revealed a significant decrease in MMP-2 and MMP-9 proteins in all treatment groups compared to the control group (Fig. 3C). The combination group showed a maximally reduced expression compared to either the CET or CXB group $(\mathrm{P}<0.05$, Fig. 3D).

Effect of CET in combination with CXB on PGE2 production and VEGF expression in HSC3 cells. To examine the effect of $\mathrm{CET}$ in combination with $\mathrm{CXB}$ on $\mathrm{PGE} 2$ production in HSC3 cells, ELISA was performed. As shown in Fig. 4A, all 


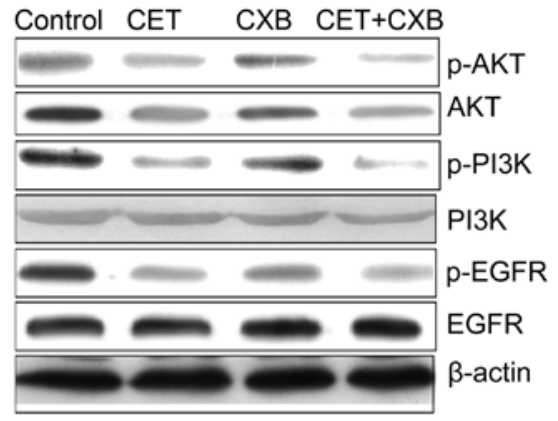

Figure 5. Effect of cetuximab (CET) in combination with celecoxib (CXB) on epidermal growth factor receptor (EGFR) downstream signaling molecules. Treatment of cells for $24 \mathrm{~h}$ with CET in combination with CXB further reduced the expression levels of p-EGFR, p-PI3K and p-Akt in the HSC3 cell line. Blots were reprobed for $\beta$-actin to normalize each lane for protein content.

treatment groups inhibited PGE2 production when compared with the control group. CXB in combination with CET significantly inhibited PGE2 production compared to the single drug groups $(\mathrm{P}<0.05)$.

We also determined VEGF protein expression by ELISA to evaluate the effect of CET in combination with $\mathrm{CXB}$ on VEGF expression. As shown in Fig. 4B, ELISA analysis revealed that VEGF excretion in the supernatant from all treatment groups was significantly decreased compared to the control group $(\mathrm{P}<0.05)$. Compared to single drug treatments, CET in combination with CXB significantly inhibited VEGF expression $(\mathrm{P}<0.05)$.

Effect of CET in combination with CXB on EGFR signaling. The EGFR signaling pathway plays a crucial role in cell proliferation and survival in various types of cancer; thus, we evaluated the effect of CET or CXB alone and in combination on several key downstream molecules involved in the EGFR signaling pathway by western blotting. CET and CXB alone and the combination inhibited the phosphorylation of PI3K, p-AKT and p-EGFR (Fig. 5). In addition, treatment of cells with CET combined with CXB further reduced the expression levels of the activated forms of EGFR (p-EGFR), p-PI3K and p-Akt, in the HSC3 cells.

Effect of CET in combination with CXB on tumor growth. We assessed the in vivo therapeutic efficacy of CET and CXB in female BALB mice bearing HSC3 tumor cells. Mice were sacrificed and tumor tissues were excised at the end of 7 days. Tumor weight of the animals was then measured. It was found that the tumor weight of all treatment groups was lower than that of the untreated group. Compared to the single drug groups, the tumor weight of the combination group was the lowest $(\mathrm{P}<0.05$, Fig. $6 \mathrm{~A})$. In addition, we also found that the tumor volume in the combination group was significantly lower compared with that in the single drug groups and the untreated group $(\mathrm{P}<0.05$, Fig. 6B).

To assess the efficacy of CET and CXB in modulating splenocyte proliferation, MTT assay was performed. As shown in Fig. 6C, the inhibitory rate of the CET combination treatment group was higher than that of the control group and single drug groups $(\mathrm{P}<0.05)$. In addition, we also determined tumor tissue
A

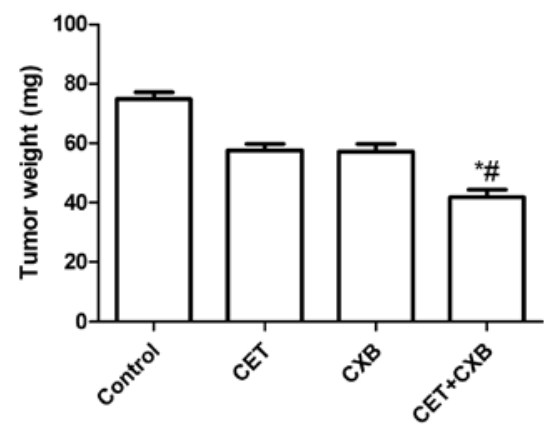

B

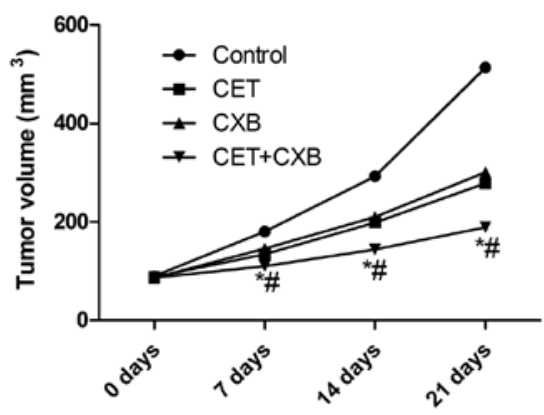

C

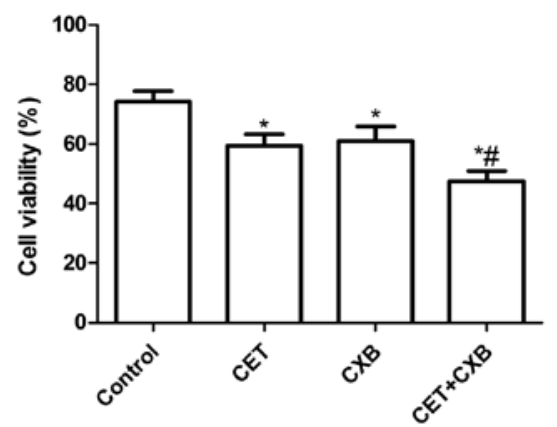

D

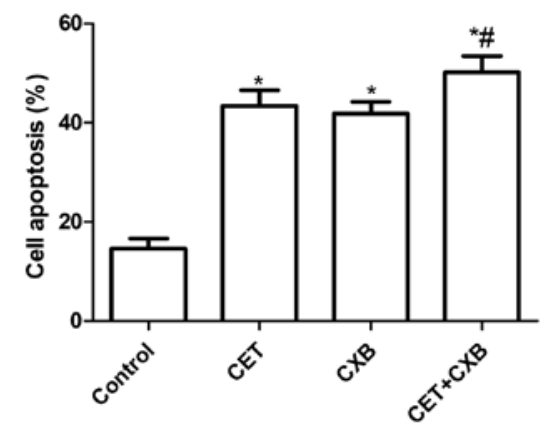

Figure 6. Antitumor activity of cetuximab (CET) or celecoxib (CXB) alone or in combination in BALB/c mice bearing HSC3 tumors. (A) Tumor weight in treated and untreated mice at the end of 7 days. (B) Tumor volume in treated and untreated mice on days 7, 14 and 21. (C) MTT assay of proliferation of splenocytes from mice. (D) Cell apoptosis was determined in vivo by TUNEL. Data are expressed as means \pm SD. ${ }^{*} \mathrm{P}<0.05$ vs. control, ${ }^{\#} \mathrm{P}<0.05$ vs. CXB alone.

cell apoptosis in vivo by TUNEL. The cell apoptosis ratios of all treatment groups in vivo were significantly higher than the ratio of the control group $(\mathrm{P}<0.05$, Fig. $6 \mathrm{D})$. Compared to the single drug groups, the cell apoptosis ratio in the combination 
groups was markedly increased. Taken together, these results demonstrated that the CET and CXB combination suppressed tumor growth of oral squamous cell carcinoma in vivo.

\section{Discussion}

In the present study, we provide convincing evidence that the combined tumor treatment with cetuximab (CET) and celecoxib (CXB) significantly reduced oral squamous cell carcinoma cell proliferation, migration and invasion and induced cell apoptosis in vitro and inhibited OSCC tumor growth in vivo, whereas the single treatments did not significantly improve the anticancer effect. Although both compounds have each been extensively studied, to our knowledge, this study is the first to show that combining a clinically applied therapy with CET and CXB inhibits OSCC tumor growth in vivo and in vitro.

The epidermal growth factor receptor (EGFR) pathway plays key roles in cell proliferation, adhesion, invasion, survival and angiogenesis. Tumors in which the EGFR pathway is activated include lung cancer, OSCC, pancreatic cancer, breast cancer and head and neck cancer (24). Antibodies and small-molecule inhibitors acting on different parts of the EGFR pathway have shown effectiveness as antineoplastic agents in these cancers (25), while monoclonal antibodies have shown low efficacy in oral squamous cell carcinoma due to intrinsic and acquired resistance (18), which require a combination of drugs. For example, Park et al showed that a combination of CET and genistein significantly inhibited tumor growth and caused a substantial growth delay in in vivo models of both cell lines while each exposure to a single-agent caused no delay of tumor growth of OSCC (26). Maseki et al found that gemcitabine and CET are effective drugs against HNSCC, and an enhanced antitumor effect may be expected when using gemcitabine in combination with CET (27). These studies revealed that CET in combination with other anticancer drugs contributes to the treatment of cancer. In the present study, we selected the combination of CET and CXB (a COX-2 inhibitor) for the treatment of OSCC as COX-2 overexpression leads to EGFR expression, which enhances tumor growth (28). In addition, preclinical data showed that upregulation of COX-2 in tumor cells resulted in increased PGE2 production and increased tumor invasiveness (29). Increased PGE2 production contributes to active EGFR and results in the activation of Ras and the mitogen-activated protein kinase (MAPK) pathway (30). Upregulation of COX-2 in tumor cells also promoted proangiogenic factors such as VEGF, bFGF, PDGF and TGF- $\beta 1$ (31), all of which favor tumor growth and dissemination. Importantly, Xia et al showed that CET in combination with CXB synergistically inhibited the growth of A549 cells and downregulated the expression of KDR and AQP1 in A549 cells (32). Jalili et al reported that tumors regressed partially and the patients Karnofsky index improved when the combination of CET and CXB was used to treat an 88-year-old man presenting a recurrent, locoregionally metastatic squamous cell carcinoma (SCC) of the right parietal region, which was resistant to radiotherapy (33). In the present study, our results revealed that the combination of low concentrations of CET and CXB significantly suppressed the proliferation, migration and invasion of HSC3 cells in vitro, and decreased PEG2 production and VEGF expression in vitro and inhibited tumor growth in vivo compared to the actions of either agent alone. These results are in agreement with previous results (32).

Chemotherapeutic drugs are most effective when administered in combination (combined chemotherapy) since chemotherapy drugs with different mechanisms of action are used, which contribute to a decreased possibility of drug resistance of cancer cells. In addition, drugs are combined having different effects, and each drug can be used at its optimal dose, without intolerable side effects (34). Currently, growing evidence suggests that the anticancer activity of standard chemotherapeutic agents can be enhanced by using CXB (35). For instance, Zhang et al showed that the combination of low concentrations of sorafenib (SOR) and CXB in A549 tumor cells significantly suppressed the proliferation in vitro and suppressed tumor growth in vivo compared to the actions of either agent alone (23). Morisaki et al showed that the combination of low concentrations of SOR $(<5 \mu \mathrm{M})$ and CXB $(<20 \mu \mathrm{M})$ resulted in enhanced inhibition of cell growth and AKT activation in hepatocellular carcinoma (HCC), and increased the induction of apoptosis of HCC cells when compared to the actions of either agent alone, and that the growth inhibitory effect was synergistic by combination index (CI) analysis (36). Jeon et al demonstrated that a combination of $\mathrm{CXB}$ and luteolin could provide superior inhibition of breast cancer cell growth than either $\mathrm{CXB}$ or luteolin treatment alone (37). Consistent with these results, our data showed that CET in combination with CXB significantly inhibited cell proliferation and induced cell apoptosis compared to each single drug. These results further confirm that $\mathrm{CXB}$ in combination with anticancer drugs can improve their antitumor effects.

In conclusion, the present study showed that CET in combination with CXB enhanced the anti-proliferative and pro-apoptotic effects on oral squamous cell carcinoma in vitro and inhibited OSCC tumor growth in a nude mouse model allowing for the use of lower doses of CET and CXB than those currently used. Therefore, it may be worthwhile to consider their combination for the treatment of oral squamous cell carcinoma and this combination further warrants evaluation in clinical trials.

\section{Acknowledgements}

This research was supported by the Youth Science Fund of the Innovation Team of the Department of Science and Technology of Jilin Province (20130522036JH).

\section{References}

1. Siegel R, Naishadham D and Jemal A: Cancer statistics, 2012. CA Cancer J Clin 62: 10-29, 2012.

2. Scully $\mathrm{C}$ and Bagan J: Oral squamous cell carcinoma overview. Oral Oncol 45: 301-308, 2009.

3. Saraswathi TR, Kavitha B and Vijayashree Priyadharsini J: Gene therapy for oral squamous cell carcinoma: an overview. Indian J Dent Res 18: 120-123, 2007.

4. Shurin MR, Umansky V, Malyguine A, et al: Cellular and molecular pathways in the tumor immunoenvironment: 3rd Cancer Immunotherapy and Immunomonitoring (CITIM) meeting, 22-25 April 2013, Krakow, Poland. Cancer Immunol Immunother 63: 73-80, 2014. 
5. Sihver W, Pietzsch J, Krause M, Baumann M, Steinbach J and Pietzsch HJ: Radiolabeled cetuximab conjugates for EGFR targeted cancer diagnostics and therapy. Pharmaceuticals 7 : 311-338, 2014

6. Olayioye MA, Neve RM, Lane HA and Hynes NE: The ErbB signaling network: receptor heterodimerization in development and cancer. EMBO J 19: 3159-3167, 2000.

7. de Bono JS and Rowinsky EK: The ErbB receptor family: a therapeutic target for cancer. Trends Mol Med 8: S19-S26, 2002 .

8. Carpenter G: Receptors for epidermal growth factor and other polypeptide mitogens. Annu Rev Biochem 56: 881-914, 1987.

9. Salomon DS, Brandt R, Ciardiello F and Normanno N: Epidermal growth factor-related peptides and their receptors in human malignancies. Crit Rev Oncol Hematol 19: 183-232, 1995.

10. Wells A: EGF receptor. Int J Biochem Cell Biol 31: 637-643, 1999.

11. Yarden Y: The EGFR family and its ligands in human cancer: signalling mechanisms and therapeutic opportunities. Eur J Cancer 37: S3-S8, 2001.

12. Wikstrand CJ, Hale LP, Batra SK, et al: Monoclonal antibodies against EGFRvIII are tumor specific and react with breast and lung carcinomas and malignant gliomas. Cancer Res 55: 3140-3148, 1995

13. Herbst RS and Langer CJ: Epidermal growth factor receptors as a target for cancer treatment: the emerging role of IMC-C225 in the treatment of lung and head and neck cancers. Semin Oncol 29: 27-36, 2002.

14. Sridhar SS, Seymour L and Shepherd FA: Inhibitors of epidermal-growth-factor receptors: a review of clinical research with a focus on non-small-cell lung cancer. Lancet Oncol 4: 397-406, 2003

15. Humblet Y: Cetuximab: an $\operatorname{IgG}(1)$ monoclonal antibody for the treatment of epidermal growth factor receptor-expressing tumours. Expert Opin Pharmacother 5: 1621-1633, 2004.

16. Harding $\mathrm{J}$ and Burtness B: Cetuximab: an epidermal growth factor receptor chemeric human-murine monoclonal antibody. Drugs Today 41: 107-127, 2005.

17. Park SJ, Kim MJ, Kim YK, Kim SM, Park JY and Myoung H: Combined cetuximab and genistein treatment shows additive anti-cancer effect on oral squamous cell carcinoma. Cancer Lett 292: 54-63, 2010.

18. Tol J, Koopman M, Cats A, et al: Chemotherapy, bevacizumab, and cetuximab in metastatic colorectal cancer. N Engl J Med 360: 563-572, 2009

19. Hattar K, Savai R, Subtil FS, et al: Endotoxin induces proliferation of NSCLC in vitro and in vivo: role of COX-2 and EGFR activation. Cancer Immunol Immunother 62: 309-320, 2013.

20. Wei D, Wang L, He Y, Xiong HQ, Abbruzzese JL and Xie K Celecoxib inhibits vascular endothelial growth factor expression in and reduces angiogenesis and metastasis of human pancreatic cancer via suppression of Sp1 transcription factor activity. Cancer Res 64: 2030-2038, 2004.

21. Jeon YW and Suh YJ: Synergistic apoptotic effect of celecoxib and luteolin on breast cancer cells. Oncol Rep 29: 819-825, 2013
22. Kao J, Sikora AT and Fu S: Dual EGFR and COX-2 inhibition as a novel approach to targeting head and neck squamous cell carcinoma. Curr Cancer Drug Targets 9: 931-937, 2009.

23. Zhang $\mathrm{H}, \mathrm{Li} \mathrm{Z}$ and Wang K: Combining sorafenib with celecoxib synergistically inhibits tumor growth of non-small cell lung cancer cells in vitro and in vivo. Oncol Rep 31: 1954-1960, 2014.

24. Ratti M and Tomasello G: Emerging combination therapies to overcome resistance in EGFR-driven tumors. Anticancer Drugs 25: 127-139, 2014.

25. Pal SK and Pegram M: Epidermal growth factor receptor and signal transduction: potential targets for anti-cancer therapy. Anticancer Drugs 16: 483-494, 2005.

26. Park SJ, Kim MJ, Kim YK, Kim SM, Park JY and Myoung H: Combined cetuximab and genistein treatment shows additive anti-cancer effect on oral squamous cell carcinoma. Cancer Lett 292: 54-63, 2010.

27. Maseki S, Ijichi K, Nakanishi H, Hasegawa Y, Ogawa T and Murakami S: Efficacy of gemcitabine and cetuximab combination treatment in head and neck squamous cell carcinoma. Mol Clin Oncol 1: 918-924, 2013.

28. Kinoshita T, Takahashi Y, Sakashita T, Inoue H, Tanabe T and Yoshimoto T: Growth stimulation and induction of epidermal growth factor receptor by overexpression of cyclooxygenases 1 and 2 in human colon carcinoma cells. Biochim Biophys Acta 1438: 120-130, 1999 .

29. Tsujii M, Kawano S and DuBois RN: Cyclooxygenase-2 expression in human colon cancer cells increases metastatic potential. Proc Natl Acad Sci USA 94: 3336-3340, 1997.

30. Sheng H, Shao J, Dixon DA, Williams CS, Prescott SM, DuBois RN and Beauchamp RD: Transforming growth factor beta1 enhances Ha-ras-induced expression of cyclooxygenase-2 in intestinal epithelial cells via stabilization of mRNA. J Biol Chem 275: 6628-6635, 2000.

31. Tsujii M, Kawano S, Tsuji S, Sawaoka H, Hori M and DuBois RN: Cyclooxygenase regulates angiogenesis induced by colon cancer cells. Cell 93: 705-716, 1998.

32. Xia H, Ye J, Bai H and Wang C: Effects of cetuximab combined with celecoxib on apoptosis and KDR and AQP1 expression in lung cancer. Zhongguo Fei Ai Za Zhi 16: 625-631, 2013 (In Chinese).

33. Jalili A, Pinc A, Pieczkowski F, Karlhofer FM, Stingl G and Wagner SN: Combination of an EGFR blocker and a COX-2 inhibitor for the treatment of advanced cutaneous squamous cell carcinoma. J Dtsch Dermatol Ges 6: 1066-1069, 2008.

34. Ullah MF: Cancer multidrug resistance (MDR): a major impediment to effective chemotherapy. Asian Pac J Cancer Prev 9: 1-6, 2008.

35. Irie T, Tsujii M, Tsuji S, et al: Synergistic antitumor effects of celecoxib with 5-fluorouracil depend on IFN-gamma. Int J Cancer 121: 878-883, 2007.

36. Morisaki T, Umebayashi M, Kiyota A, et al: Combining celecoxib with sorafenib synergistically inhibits hepatocellular carcinoma cells in vitro. Anticancer Res 33: 1387-1395, 2013.

37. Jeon YW and Suh YJ: Synergistic apoptotic effect of celecoxib and luteolin on breast cancer cells. Oncol Rep 29: 819-825, 2013. 